\section{Scottish geology for the 1980s}

\author{
W.S. McKerrow
}

Geology of Scotland, 2nd Edn.

Edited by G.Y. Craig.

Scottish Academic Press/Halsted: 1983.

Pp.472. Hbk £35, \$54.95;

pbk $£ 17.50$.

Scotland's Environment During the Last 30,000 Years.

By Robert J. Price.

Scottish Academic Press/Columbia

University Press: 1983.

Pp.224. Hbk £27.50, \$41.50; pbk $£ 15$.

Geologically, Scotland is a small but significant part of the world. Its standing is due to a combination of factors: diverse geology, good exposures and attractive landscape for the field geologist, and especially its wealth of geological literature. James Nicol was very wrong when he stated (in his 1844 Guide to the Geology of Scotland) that "....in a country which has been so frequently investigated by eminent geologists, it is evident that little absolutely new can be expected". The reverse is true: the better documented the geology, the easier it is to make further advances. Scottish studies in deformation, metamorphism, igneous petrogenesis and Palaeozoic stratigraphy have all led the world at different times during the past two centuries. The names of Hutton, Judd, Geikie, Lapworth, Peach and Horne, Barrow, Harker, Bailey, Richey, Read and Kennedy help to remind us of some of the advances which came from Scotland. What is Scotland doing for geology today?

Since 1965, when Craig produced the first edition of Geology of Scotland, our understanding of geological processes has progressed greatly. We now know more about the rates of crustal processes, structural lineaments, the deep crust, palaeolatitudes, heat flow and the continental shelf around Scotland. We also have plate tectonic models to assist us in finding analogues (from other times and other continents) to some of the major tectonic events in the geological history of the area. Most of these advances are recorded in the new edition, but the different contributors each have their own personal approach to the new facts and the new ideas. We now have much clearer views on the significance of many rocks and structures which previously were baffling or just interpreted wrongly.

Of the 12 authors, seven contributed to the first edition and have attained somewhat variable success in bringing their essays up to date. All five new contributors have maintained the high standards set in the first edition. In his introductory chapter, Harris gives a clear outline of Scottish geological development, much enhanced by his table of events (Fig. 1.2). It is unfortunate that the sections on Tertiary growth and on geomorphic evolution (present in the first edition) have disappeared; these are relatively neglected fields that should not be ignored.

The presentation and standard of editing is, in general, so good that it is perhaps unnecessary to stress the few failures. A stronger hand might have removed some hangovers from the first edition, such as the multiple discussions of the Highland Border Group (presented separately on pp. 84,98 and 109-110) and of the Ballantrae Volcanic Group (pp. 110, 152 and 174-175). The editor might also have established some standardization of such a crucial term as "Caledonian Orogeny", where Scottish geologists should give a clear lead. Now we know that many orogenies extend over long periods of time (few are short-lived as Stille thought), we badly need to get our definitions sorted out.

One achievement of the book is that diverse parts of geology have been brought together to form a coherent unity, although this does break down in a few places. The new contributions by Brown and Mykura respectively provide excellent summaries of Devonian magmatism and stratigraphy, as do the chapters by Francis on the Carboniferous and by Lovell on the Permian and Triassic, but it is a pity that these accounts of the Late Palaeozoic igneous rocks and sediments have not been more closely integrated.

The contribution by Emeleus on Tertiary igneous rocks contains clear reviews of the latest work in geochemistry relevant to petrogenesis. This chapter takes cognizance of recent geophysical studies, though in general geophysics is not well discussed throughout the book - such a failing is to be regretted, especially in view of much recent work on the deep geology of Scotland.
Sissons gives a brief summary of the complex developments in Scotland during the Quaternary. His ability to condense a large amount of data becomes evident by study of another new contribution to Scottish geology, Scotland's Environment During the Last 30,000 Years. The author, R.J. Price, states (p.23) that:

This book is concerned not only with the geomorphological and marine sedimentary record but with the broad environmental changes which can be identified as a result of detailed investigations not only in these fields but in all aspects of the geomorphological, stratigraphical, palaeontological and archaeological record.

Price lives up to his claim in discussions of geomorphology and chronology, but some geologists will find him weak on sedimentology.

Price emphasizes a most important geological truth (pp. 8-11): the record is best in the oceans, where sedimentation has been more or less continuous; it is next best on the shelf, then on coasts and low ground, but it is almost non-existent in mountains. As a result, the key to many recent advances in Quaternary stratigraphy lies on the sea floor. Will river terraces be the next sediments to repay renewed investigation? They have produced many good results in the English Midlands; could they not also do the same in Scotland?

Both books reviewed here are clearly presented and well illustrated, with full lists of references. They should prove useful to a wide readership: the scientist, the student and the scientifically orientated tourist. Scotland has still further significant contributions to make to geology, and these two books will help to provide a sound basis for future work.

W.S. McKerrow is a Lecturer in the Department of Geology and Mineralogy at the University of Oxford, and a Fellow of Wolfson College.

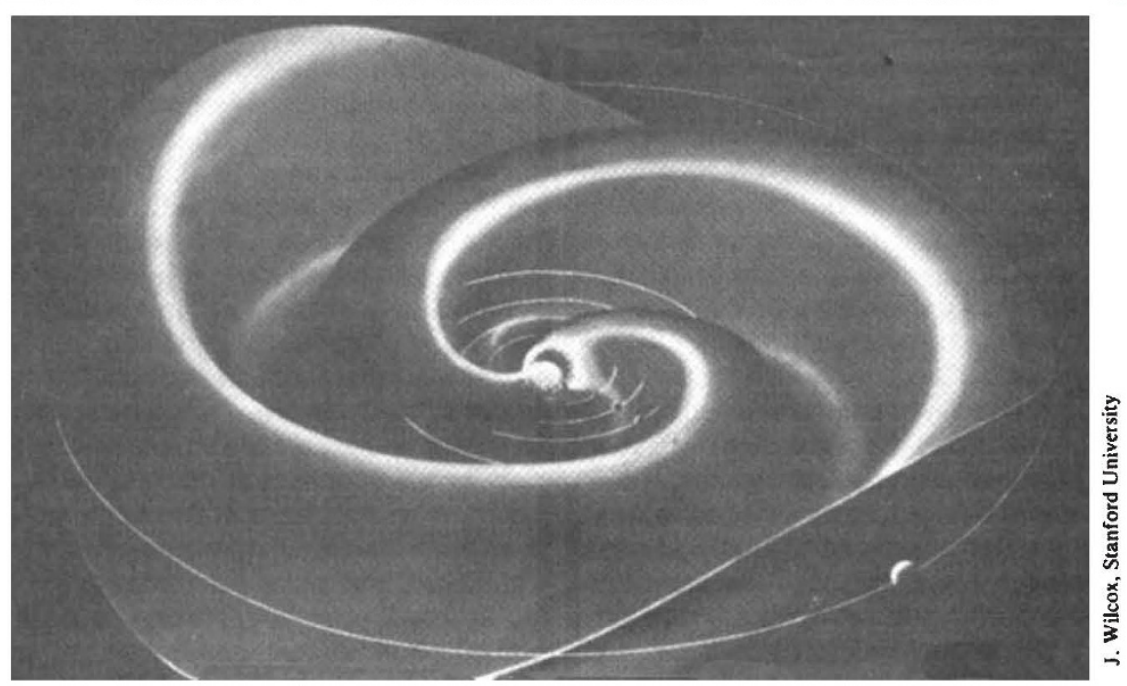

An artist's conception of the interplanetary medium out to the orbit of Jupiter, showing the spiral structure of the interplanetary magnetic field and the wavy shape of the interplanetary neutral sheet. (The neutral sheet, which is invisible, divides magnetic field lines pointing towards the Sun from those pointing away.) The illustration is taken from Astronomy from Space: Sputnik to Space Telescope, edited by James Cornell and Paul Gorenstein, and recently published by MIT Press. Price is $\$ 17.50, £ 15.75$. 